\title{
Incomplete Contracts and the Product Cycle
}

\section{Citation}

Antras, Pol. 2005. Incomplete contracts and the product cycle. American Economic Review 95(4): 1054-1073.

\section{Published Version}

http://dx.doi.org/10.1257/0002828054825600

\section{Permanent link}

http://nrs.harvard.edu/urn-3:HUL.InstRepos:3196324

\section{Terms of Use}

This article was downloaded from Harvard University's DASH repository, and is made available under the terms and conditions applicable to Other Posted Material, as set forth at http:// nrs.harvard.edu/urn-3:HUL.InstRepos:dash.current.terms-of-use\#LAA

\section{Share Your Story}

The Harvard community has made this article openly available.

Please share how this access benefits you. Submit a story.

\section{Accessibility}




\title{
Incomplete Contracts and the Product Cycle
}

\author{
By Pol Antràs*
}

\begin{abstract}
I present a model in which the incomplete nature of contracts governing international transactions limits the extent to which the production process can be fragmented across borders. Because of contractual frictions, goods are initially manufactured in the same country where product development takes place. Only when the good becomes sufficiently standardized is the manufacturing stage of production shifted to a low-wage foreign location. Solving for the optimal organizational structure, I develop a new version of the product cycle hypothesis in which manufacturing is shifted abroad first within firm boundaries, and only at a later stage to independent foreign firms. (JEL D23, F12, F14, F21, F23, L22, L33)
\end{abstract}

In an enormously influential article, Raymond Vernon (1966) described a natural life cycle for the typical commodity. Most new goods, he argued, are initially manufactured in the country where they are first developed, with the bulk of innovations occurring in the industrialized North. Only when the appropriate designs have been worked out and the production techniques have been standardized is the locus of production shifted to the less developed South, where wages are lower. Vernon emphasized the role of multinational firms in the international transfer of technology. In his formulation of a product's life cycle, the shift of production to the South is a profit-maximizing decision from the point of view of the innovating firm.

The "product cycle hypothesis" soon gave rise to an extensive empirical literature that searched for evidence of the patterns suggested by Vernon. ${ }^{1}$ The picture emerging from this literature turned out to be much richer than Vernon originally envisioned. The evidence indeed supports the existence of product cycles, but it has become clear that foreign direct investment by multinational firms is not the only vehicle of production transfer to the South. The literature has identified several instances

\footnotetext{
${ }^{1}$ See William Gruber et al. (1967), Seev Hirsch (1967), Louis T. Wells, Jr. (1969), and Thomas G. Parry (1975) for early tests of the theory.
} 
in which technologies have been transferred to the South through licensing, subcontracting, and other similar arm's length arrangements. More interestingly, several studies have pointed out that the choice between intrafirm and market transactions is significantly affected by both the degree of standardization of the technology as well as by the transferor's resources devoted to product development. $^{2}$ In particular, overseas assembly of relatively new and unstandardized products tends to be undertaken within firm boundaries, while innovators seem more willing to resort to licensing and subcontracting in standardized goods with little product development requirements.

The product cycle hypothesis has also attracted considerable attention among international trade theorists eager to explore the macroeconomic and trade implications of Vernon's insights. Paul Krugman (1979) developed a simple model of trade in which new goods are produced in the industrialized North and exchanged for old goods produced in the South. In order to concentrate on the effects of product cycles on trade flows and relative wages, Krugman (1979) specified a very simple form of technological transfer, with new goods becoming old goods at an exogenous rate. This "imitation lag," as he called it, was later endogenized by Gene M. Grossman and Elhanan Helpman (1991a,b) using the machinery developed by the endogenous growth literature. In particular, Grossman and Helpman (1991a,b) developed models in which purposeful innovation and imitation gave rise to endogenous product cycles, with the timing of production transfer being a function of the imitation effort exerted by firms in the South. ${ }^{3}$ As the empirical literature on the product cycle suggests, however, the bulk of technology transfer is driven by voluntary decisions of Northern firms, which choose to undertake offshore production within firm boundaries or transact with independent subcontractors or licensees. ${ }^{4}$

In this paper, I provide a theory of the product cycle that is much more akin to Vernon's (1966) original formulation and that delivers implications that are very much in line with the findings of the empirical literature discussed above. In the model, goods are produced combining a hi-tech input, which I associate with product development, and a low-tech input, which is meant to capture the simple assembly or manufacturing of the good. As in Grossman and Helpman (1991a,b), the

\footnotetext{
${ }^{2}$ See, for instance, Robert W. Wilson (1977), Edwin Mansfield et al. (1979), Mansfield and Anthony A. Romeo (1980), and William H. Davidson and Donald G. McFetridge (1984, 1985). These studies will be discussed in more detail in section III below.

${ }^{3}$ See Richard A. Jensen and Marie C. Thursby (1987), and Paul S. Segerstrom et al. (1990) for related theories of endogenous product cycles.

${ }^{4}$ Grossman and Helpman (1991b) claimed that purposeful imitation was an important driving force in the transfer of production of microprocessors from the United States and Japan to Taiwan and Korea. Based on recent studies, I will argue below that even in the case of the electronics industry, the spectacular increase in the market share of Korean producers might be better explained by technology transfer from foreign-based firms than by simple imitation by domestic firms in Korea.
} 
North is assumed to have a high enough comparative advantage in product development so as to ensure that this activity is always undertaken there. My specification of technology differs, however, from that in Grossman and Helpman (1991a,b) in that I treat product development as a continuously active sector along the life cycle of a good. The concept of product development used here is therefore quite broad and is meant to include, among others, the development of ideas for improving existing products, as well as their marketing and advertising. Following Vernon (1966), this specification of technology enables me to capture the standardization process of a good along its life cycle. More specifically, I assume that the contribution of product development to output (as measured by the output elasticity of the hi-tech input) is inversely related to the age or maturity of the good. Intuitively, the initial phases of a product's life cycle entail substantial testing and re-testing of prototypes as well as considerable marketing efforts to make consumers aware of the existence of the good. As the good matures and production techniques become standardized, the mere assembly of the product becomes a much more significant input in production.

Following Vernon (1966) and contrary to Grossman and Helpman (1991a,b), I allow Northern firms to split the production process internationally and transact with manufacturing plants in the South. ${ }^{5}$ With no frictions to the international fragmentation of the production process, I show that the model fails to deliver a product cycle. Intuitively, provided that labor is paid a lower wage in the South than in the North, manufacturing will be shifted to the South even for the most unstandardized, product-development intensive goods. Vernon (1966) was well aware that his theory required some type of friction that delayed offshore assembly. In fact, he argued that in the initial phase of a product's life cycle, overseas production would be discouraged by a low price elasticity of demand, the need for a thick market for inputs, and the need for swift and effective communication between producers and suppliers.

This paper will instead push the view that what limits the international fragmentation of the production process is the incomplete nature of contracts governing international transactions. Building on the seminal work of Oliver E. Williamson (1985) and Sanford J. and Oliver D. Hart (1986), I show that the presence of incomplete contracts creates hold-up problems, which in turn give rise to suboptimal relationship-specific investments by the parties involved in an international transaction. The product development manager of a Northern firm can alleviate this type

\footnotetext{
${ }^{5}$ There is a recent literature in international trade documenting an increasing international disintegration of the production process (cf, Robert C. Feenstra, 1998; Kei-Mu Yi, 2003). A variety of terms have been used to refer to this phenomenon: "international outsourcing", "slicing of the value chain", "vertical specialization", "global production sharing", and many others. Feenstra (1998) discusses the widely cited example of Nike, which subcontracts most parts of its production process to independent manufacturing plants in Asia.
} 
of distortions by keeping the manufacturing process in the North, where contracts can be better enforced. In choosing between domestic and overseas manufacturing, the product development manager therefore faces a trade-off between the lower costs of Southern manufacturing and the higher incomplete-contracting distortions associated with it. This trade-off is shown to lead naturally to the emergence of product cycles: when the good is new and unstandardized, Southern production is very unattractive because it bears the full cost of incomplete contracting (which affects both the manufacturing and the product development stages of production) with little benefit from the lower wage in the South. Conversely, when the good is mature and requires very little product development, the benefits from lower wages in the South fare much better against the distortions from incomplete contracting, and if the Southern wage is low enough, the good is manufactured in the South.

Following the property-rights approach to the theory of the firm (Grossman and Hart, 1986; Hart and John H. Moore, 1990), the same force that creates product cycles in the model, i.e., incomplete contracts, opens the door to a parallel analysis of the determinants of ownership structure, which I carry out in section II. As in Grossman and Hart (1986), I associate ownership with the entitlement of some residual rights of control. When parties undertake noncontractible, relationship-specific investments, the allocation of these residual rights has a critical effect on each party's ex-post outside option, which in turn determines each party's ex-ante incentives to invest. Ex-ante efficiency (i.e., transaction-cost minimization) is shown to dictate that residual rights be controlled by the party whose investment contributes most to the value of the relationship. In terms of the model, the attractiveness for a Northern product-development manager of integrating the transfer of production to the South is shown to be increasing in the output elasticity of product development, and thus decreasing in the maturity of the good at the time of the transfer.

As a result, a new version of the product cycle emerges. If the maturity at which manufacturing is shifted to the South is low enough, production will be transferred internally to a wholly-owned foreign affiliate in the South, and the Northern firm will become a multinational firm. In such case, only at a later stage in the product's life cycle will the product development manager find it optimal to give away the residual rights of control, and assign assembly to an independent subcontractor in the South, an arrangement which is analogous to the Northern firm licensing its technology (hi-tech input). For a higher maturity of the good at the time of the transfer, the model predicts that the transfer to the South will occur directly at arm's length, and multinationals will not arise. In section III, I discuss several cross-sectional and time-series implications of the model and relate 
them to the empirical literature on the product cycle. For instance, the model is shown to be useful for understanding the evolution of the Korean electronics industry after the Korean War.

The rest of the paper is structured as follows. Section I develops a simple dynamic model that shows how the presence of incomplete contracts gives rise to product cycles. In section II, I allow for intrafirm production transfers and describe the richer product life-cycle that emerges from it. Section III reviews the findings of the empirical literature on the product cycle and relates them to the predictions of the model. Section IV offers some concluding comments.

\section{Incomplete Contracts and the Life Cycle of a Product}

This section develops a simple model in which a product development manager decides how to organize production of a particular good, taking the behavior of other producers as well as wages as given. I will first analyze the static problem, and then show how a product cycle emerges in a simple dynamic extension in which the good gets standardized over time.

\section{A. Set-up}

Consider a world with two countries, the North and the South, and a single good $y$ produced only with labor. I denote the wage rate in the North by $w^{N}$ and that in the South by $w^{S}$. Consumer preferences are such that the unique producer of good $y$ faces the following iso-elastic demand function:

$$
y=\lambda p^{-1 /(1-\alpha)}, \quad 0<\alpha<1
$$

where $p$ is the price of the good and $\lambda$ is a parameter that the producer takes as given. ${ }^{6}$

Production of good $y$ requires the development of a special and distinct hi-tech input $x_{h}$, as well as the production of a special and distinct low-tech input $x_{l}$. As discussed in the introduction, the hi-tech input is meant to comprise research and product development, marketing, and other similar skill-demanding tasks. The low-tech input is instead meant to capture the mere manufacturing or assembly of the good. Specialized inputs can be of good or bad quality. If any of the two inputs is of bad quality, the output of the final good is zero. If both inputs are of good quality, production

\footnotetext{
${ }^{6}$ This demand function is derived from preferences in the general-equilibrium version of the model presented in the Appendix.
} 
of the final good requires no additional inputs and output is given by:

$$
y=\zeta_{z} x_{h}^{1-z} x_{l}^{z}, \quad 0 \leq z \leq 1
$$

where $\zeta_{z}=z^{-z}(1-z)^{-(1-z)}$.

The unit cost function for producing the hi-tech input varies by country. In the North, production of one unit of a good-quality, hi-tech input requires the employment of one unit of Northern labor. The South is much less efficient at producing the hi-tech input. For simplicity, the productivity advantage of the North is assumed large enough to ensure that $x_{h}$ is only produced in the North. Meanwhile, production of one unit of good-quality, low-tech input also requires labor, but the unit input requirement is assumed to be equal to 1 in both countries. Production of any type of bad-quality input can be undertaken at a positive but negligible cost. All types of inputs are assumed to be freely tradable.

There are two types of producers: a research center and a manufacturing plant. A research center is defined as the producer of the hi-tech input and will thus always locate in the North. I assume for now that the research center needs to contract with an independent manufacturing plant for the provision of the low-tech input. In the next section, I will let the research center obtain the low-tech input from an integrated plant.

As discussed in the introduction, I allow for an international fragmentation of the production process. Before any investment is made, a research center decides whether to produce a hi-tech input, and if so, whether to obtain the low-tech input from an independent manufacturing plant in the North or from one in the South. Upon entry, the manufacturer makes a lump-sum transfer $T$ to the research center. Because, ex-ante, there is a large number of identical, potential manufacturers of the good, competition among them will make $T$ adjust so as to make the chosen manufacturer break even. ${ }^{7}$ The research center chooses the location of manufacturing to maximize its ex-ante profits, which include the transfer.

Investments are assumed to be relationship-specific. The research center tailors the hi-tech input specifically to the manufacturing plant, while the low-tech input is customized according to the specific needs of the research center. In sum, the investments in labor needed to produce $x_{h}$ and $x_{l}$ are incurred upon entry and are useless outside the relationship.

\footnotetext{
${ }^{7}$ When $y$ is produced by the manufacturing plant, the transfer $T$ can be interpreted as a lump-sum licensing fee for the use of the hi-tech input. The presence of this transfer simplifies the general-equilibrium model outlined in the Appendix. For the results in the present section, it would suffice to assume that no firm is cash-constrained, so that the equilibrium location of manufacturing maximizes the joint value of the relationship.
} 
The setting is one of incomplete contracts in situations of international production sharing. In particular, it is assumed that only when both inputs are produced in the same country can an outside party distinguish between a good-quality and a bad-quality intermediate input. ${ }^{8}$ Hence, the manager of the research center and that of a Southern manufacturing plant cannot sign an enforceable contract specifying the purchase of a certain type of intermediate input for a certain price. If they did, the party receiving a positive payment would have an incentive to produce the bad-quality input at the negligible cost. It is equally assumed that no outside party can verify the amount of ex-ante investments in labor. If these were verifiable, the managers could contract on them, and the cost-reducing benefit of producing a bad-quality input would disappear. For the same reason, it is assumed that the parties cannot write contracts contingent on the volume of sale revenues obtained when the final good is sold. The only contractible ex-ante is the transfer $T$ between the parties. ${ }^{9}$

When the research center chooses to transact with a manufacturing plant in the North, the fact that labor investments are not contractible is irrelevant because the parties can always appeal to an outside party to enforce quality-contingent contracts. In contrast, when the low-tech input is produced by a plant in the South, no enforceable contract will be signed ex-ante and the two parties will bargain over the surplus of the relationship after the inputs have been produced. At this point, the quality of the inputs is observable to both parties and thus the costless bargaining will yield an ex-post efficient outcome. I model this ex-post bargaining as a Symmetric Nash Bargaining game in which the parties share equally the ex-post gains from trade. ${ }^{10}$ Because the inputs are tailored specifically to the other party in the transaction, if the two parties fail to agree on a division of the surplus, both are left with nothing.

This completes the description of the model. The timing of events is summarized in Figure 1.

\section{[FIGURE 1 ABOUT HERE]}

\section{B. Firm Behavior}

\footnotetext{
${ }^{8}$ This can be interpreted as a physical constraint imposed on the outside party, which might not be able to verify the quality of both inputs when these are produced in distant locations More generally, the assumption is meant to capture broader contractual difficulties in international transactions, such as ambiguous jurisdiction, language conflicts, or, more simply, weak protection of property rights in low-wage countries.

${ }^{9}$ I take the fact that contracts are incomplete as given. Philippe Aghion et al. (1994), Georg Nöldeke and Klaus M. Schmidt (1995) and others, have shown that allowing for specific-performance contracts may lead to efficient ex-ante relationship-specific investments. Nevertheless, Yeon-Koo Che and Donald B. Hausch (1997) have identified conditions under which specific-performance contracts do not lead to first-best investment levels and may actually have no value.

${ }^{10}$ In Antràs (2004), I extend the analysis to the case of Generalized Nash Bargaining.
} 
As discussed above, the North has a sufficiently high productivity advantage in producing the hitech input to ensure that $x_{h}$ is produced there. The decision of where to produce the low-tech input is instead nontrivial. In his choice, the manager of the research center compares the ex-ante profits associated with two options, which I analyze in turn.

\section{(a) Manufacturing by an Independent Plant in the North}

Consider first the case of a research center that decides to deal with an independent manufacturing plant in the North. In that case, the two parties can write an ex-ante quality-contingent contract that will not be renegotiated ex-post. The initial contract stipulates production of good-quality inputs in an amount that maximizes the research center's ex-ante profits, which from equations (1) and (2), and taking account of the transfer $T$, are given by $\pi^{N}=\lambda^{1-\alpha} \zeta_{z}^{\alpha} x_{h}^{\alpha(1-z)} x_{l}^{\alpha z}-w^{N} x_{h}-w^{N} x_{l}$. It is straightforward to check that this program yields the following optimal price for the final good:

$$
p^{N}(z)=\frac{w^{N}}{\alpha}
$$

Because the research center faces a constant elasticity of demand, the optimal price is equal to a constant mark-up over marginal cost. Ex-ante profits for the research center are in turn equal to

$$
\pi^{N}(z)=(1-\alpha) \lambda\left(\frac{w^{N}}{\alpha}\right)^{-\alpha /(1-\alpha)}
$$

\section{(b) Manufacturing by an Independent Plant in the South}

Consider next the problem faced by a research center that decides to transact with a plant in the South. As discussed above, in this case the initial contract only stipulates the transfer $T$. The game played by the manager of the research center and that of the manufacturing plant is solved by backwards induction. If both producers make good-quality intermediate inputs and the firms agree in the bargaining, the potential revenues from the sale of the final good are $R=\lambda^{1-\alpha} \zeta_{z}^{\alpha} x_{h}^{\alpha(1-z)} x_{l}^{\alpha z}$. In contrast, if the parties fail to agree in the bargaining, both are left with nothing. The quasi-rents of the relationship are therefore equal to sale revenues, i.e., $R$. The Nash bargaining leaves each manager with one-half of these quasi-rents. Rolling back in time, the research center manager sets $x_{h}$ to maximize $\frac{1}{2} R-w^{N} x_{h}$, while the manufacturing plant simultaneously chooses $x_{l}$ to maximize $\frac{1}{2} R-w^{S} x_{l} \cdot{ }^{11}$ Combining the first-order conditions of these two programs yields the following

\footnotetext{
${ }^{11}$ It is easily checked that in equilibrium both parties receive a strictly positive ex-post payoff from producing a good-quality input. It follows that bad-quality inputs are never produced.
} 
optimal price for the final good:

$$
p^{S}(z)=\frac{2\left(w^{N}\right)^{1-z}\left(w^{S}\right)^{z}}{\alpha}
$$

If parties could write complete contracts in international transactions, the research center would instead set a price equal to $\left(w^{N}\right)^{1-z}\left(w^{S}\right)^{z} / \alpha$. The overinflated price reflects the distortions arising from incomplete contracting. Intuitively, because in the ex-post bargaining the parties fail to capture the full marginal return to their investments, they will tend to underinvest in $x_{h}$ and $x_{l}$. As a result, output will tend to be suboptimal and the move along the demand function will also be reflected in an inefficiently high price.

Setting $T$ so as to make the manufacturing plant break even leads to the following expression for the research center's ex-ante profits:

$$
\pi^{S}(z)=\left(1-\frac{1}{2} \alpha\right) \lambda\left(\frac{2\left(w^{N}\right)^{1-z}\left(w^{S}\right)^{z}}{\alpha}\right)^{-\alpha /(1-\alpha)}
$$

\section{The Equilibrium Choice}

From comparison of equations (3) and (4), it follows that the low-tech input will be produced in the South only if $A(z) \leq \omega \equiv w^{N} / w^{S}$, where

$$
A(z) \equiv\left(\frac{1-\alpha}{\left(1-\frac{1}{2} \alpha\right)\left(\frac{1}{2}\right)^{\alpha /(1-\alpha)}}\right)^{(1-\alpha) / \alpha z}
$$

It is straightforward to show that $A(z)$ is non-increasing in $z$ for $z \in[0,1]$, with $\lim _{z \rightarrow 0} A(z)=+\infty$ and $A(1)>1 .{ }^{12}$ This implies that (i) for high enough product-development intensities of the final good, manufacturing is necessarily assigned to a manufacturing plant in the North; and (ii) unless the wage in the North is higher than that in the South, manufacturing by an independent plant in the South will never be chosen. Intuitively, the benefits of Southern assembly are able to offset the distortions created by incomplete contracting only when the manufacturing stage is sufficiently important in production or when the wage in the South is sufficiently lower than that in the North. To make matters interesting, I assume that:

Assumption 1: $\omega>A(1)>1$.

\footnotetext{
${ }^{12}$ This follows from the fact that $(1-\alpha x) x^{\alpha /(1-\alpha)}$ is increasing in $x$ for $\alpha \in(0,1)$ and $x \in(0,1)$.
} 
In Antràs (2004), I show that this condition necessarily holds in a simple general-equilibrium extension of the model, in which the relative wage $\omega$ is endogenously pinned down. Intuitively, in the general equilibrium the relative wage in the North necessarily adjusts to ensure positive labor demand in the South. This extension is briefly outlined in the Appendix. A salient feature of the analysis is that as long as contracts governing international transactions are incomplete, the equilibrium wage in the North necessarily exceeds that in the South. ${ }^{13}$

\section{[FIGURE 2 ABOUT HERE]}

Assumption 1 ensures that $\pi^{N}(z)<\pi^{S}(z)$ for sufficiently high $z \in[0,1]$. Figure 2 depicts the profit-maximizing choice of location as a function of $z$. It is apparent that:

Lemma 1 Under Assumption 1, there exists a unique threshold $\bar{z} \in(0,1)$ such that the low-tech input is produced in the North if $z<\bar{z} \equiv A^{-1}(\omega)$, while it is produced in the South if $z>\bar{z} \equiv$ $A^{-1}(\omega)$, where $A(z)$ is given by equation (5) and $\omega$ is the relative wage in the North.

From direct inspection of Figure 2, it is clear that an increase in the relative wage in the North reduces the threshold $\bar{z}$. Intuitively, an increase in $\omega$ makes Southern manufacturing relatively more profitable and leads to a reduction in the measure of product-development intensities for which the whole production process stays in the North.

\section{Dynamics: The Product Cycle}

As discussed in the introduction, one of the premises of Vernon's (1966) original product-cycle hypothesis is that as a good matures throughout its life cycle, it becomes more and more standardized. ${ }^{14}$ Vernon believed that the unstandardized nature of new goods was crucial for understanding that they would be first produced in a high-wage country.

To capture this standardization process in a simple way, consider the following simple dynamic extension of the static model developed above. Time is continuous, indexed by $t$, with $t \in[0, \infty)$. Consumers are infinitely lived and, at any $t \in[0, \infty)$, their preferences for good $y$ are captured

\footnotetext{
${ }^{13}$ Another appealing characteristic of the general-equilibrium analysis is that the cross-sectional picture that emerges from the model is very similar to that in the classical Ricardian model with a continuum of goods of Rudiger Dornbusch et al. (1977).

${ }^{14}$ In discussing previous empirical studies on the location of industry, Vernon wrote: "in the early stages of introduction of a new good, producers were usually confronted with a number of critical, albeit transitory, conditions. For one thing, the product itself may be quite unstandardized for a time; its inputs, its processing, and its final specifications may cover a wide range. Contrast the great variety of automobiles produced and marketed before 1910 with the thoroughly standardized product of the 1930s, or the variegated radio designs of the 1920s with the uniform models of the 1930s." (Vernon, 1966, p. 197).
} 
by the demand function (1). The relative wage $\omega$ is assumed to be time-invariant. ${ }^{15}$ The output elasticity of the low-tech input is instead assumed to increase through time. In particular, this elasticity is given by

$$
z(t)=h(t), \text { with } h^{\prime}(t)>0, h(0)=0, \text { and } \lim _{t \rightarrow \infty} h(t)=1 .
$$

I therefore assume that the product-development intensity of the good is inversely related to its maturity. Following the discussion in the introduction, this is meant to capture the idea that most goods require a lot of $\mathrm{R} \& \mathrm{D}$ and product development in the early stages of their life cycle, while the mere assembling or manufacturing becomes a much more significant input in production as the good matures. I will take these dynamics as given, but it can be shown that, under Assumption 1, profits for the Northern research center are weakly increasing in $z$. It follows that the smooth process of standardization specified here could, in principle, be derived endogenously in a richer framework that incorporated some costs of standardization. ${ }^{16}$ Finally, I assume that the structure of firms is such that when Southern assembly is chosen, the game played by the two managers can be treated as a static one and we can abstract from an analysis of reputational equilibria. This is a warranted assumption when the separation rate for managers is high enough or when future profit streams are sufficiently discounted.

With this simplified, dynamic set-up, the cut-off level $\bar{z} \equiv A^{-1}(\omega)$ is time-invariant, and the following result is a straightforward implication of Lemma 1:

Proposition 1 The model displays a product cycle. When the good is relatively new or unstandardized, i.e., $t \leq h^{-1}(\bar{z})$, the manufacturing stage of production takes place in the North. When the good is relatively mature or standardized, i.e., $t>h^{-1}(\bar{z})$, manufacturing is undertaken in the South.

Consider, for instance, the following specification of the standardization process:

$$
z(t)=h(t)=1-e^{-t / \theta}
$$

where $1 / \theta$ measures the rate at which $1-z$ falls towards zero, i.e., the rate of standardization. With

\footnotetext{
${ }^{15}$ The latter assumption is relaxed in the general equilibrium version of the model developed in Antràs (2004) and sketched in the Appendix.

${ }^{16}$ For instance, if such costs were increasing in $d z / d t$, then a discrete increase in $z$ would be infinitely costly. A full fledged modeling of the standardization decision is left for future research.
} 
this functional form, the whole production process remains in the North until the product reaches an age equal to $\theta \ln \left(\frac{1}{1-\bar{z}}\right)$, at which point manufacturing is shifted to the South. Naturally, production of the low-tech input is transferred to the South earlier, the higher is the speed of standardization, $1 / \theta$, and the lower is the threshold intensity $\bar{z}$. Furthermore, because the cut-off $\bar{z}$ is itself a decreasing function of $\omega$, it follows that the higher is the relative wage in the North, the earlier will production transfer occur. ${ }^{17}$

As argued in the introduction, the fact that international contracts are not perfectly enforceable is important for product cycles to emerge. To illustrate this, consider the case in which the quality of intermediate inputs were verifiable by an outside court even in international transactions, so that the manager of the research center and that of the Southern manufacturing plant could also write enforceable contracts. It is straightforward to check that, in such case, profits for the research center would be $\pi^{S}(z)=(1-\alpha) \lambda\left(\left(w^{N}\right)^{1-z}\left(w^{S}\right)^{z} / \alpha\right)^{-\alpha /(1-\alpha)}$. Comparing this expression with equation (3), it follows that assembly in the South would be chosen only if $\omega \geq 1$ (this is the analog of Assumption 1 above). If $\omega>1$, profits would satisfy $\pi^{N}(z) \leq \pi^{S}(z)$ for all $z \in[0,1]$, with strict inequality for $z>0$. The production process would therefore be broken up from time 0 and no product cycles would arise. If instead $\omega=1, \pi^{N}(z)$ and $\pi^{S}(z)$ would be identical for all $z \in[0,1]$ and the location of manufacturing would be indeterminate, in which case product cycles would emerge with probability zero.

Arguably, incomplete contracting is just one of several potential frictions that would make manufacturing stay in the North for a period of time. It is important to emphasize, however, that not any type of friction would give rise to product cycles in the model. The fact that incomplete contracts distort both the manufacturing stage and the product development stage in production is of crucial importance. For instance, introducing a transport cost or a communication cost that created inefficiencies only in the provision of the low-tech input would not suffice to give rise to product cycles in the model. In this paper, I choose to emphasize the role of incomplete contracts because they are an important source of frictions in the real world and, also, because they are a very useful theoretical tool for understanding firm boundaries, which are the focus of the next section. The type of organizational cycles unveiled by the empirical literature on the product cycle could not easily be rationalized in theoretical frameworks in which production transfer to low-

\footnotetext{
${ }^{17}$ Vernon (1966) hypothesized instead that before being transferred to low-wage countries, production would first be located in middle-income countries for a period of time. An important point to notice is that in doing the comparative statics with respect to $\omega$, I have held the contracting environment constant. Recent empirical studies suggest that countries with better legal systems tend to have higher levels of per-capita income (Robert E. Hall and Charles I. Jones, 1999; Daron Acemoglu et al., 2001). If I allowed for this type of correlation in the model, production might not be transferred earlier, the higher $\omega$.
} 
wage countries was delayed merely by transport costs or communication costs. ${ }^{18}$ Instead, they will emerge naturally in the extension below.

\section{Firm Boundaries and the Product Cycle}

Consider next the same set-up as in the previous section with the following new feature. The research center is now given the option of vertically integrating the manufacturing plant and, in the case of Southern assembly, becoming a multinational firm. Following the property-rights approach of the theory of firm, vertical integration has the benefit of strengthening the ex-post bargaining power of the integrating party (the research center), but the cost of reducing the ex-post bargaining power of the integrated party (the manufacturing plant). In particular, by integrating the production of the low-tech input, the manager of the manufacturing plant becomes an employee of the research center manager. This implies that if the manufacturing plant manager refuses to trade after the sunk costs have been incurred, the research center manager now has the option of firing the overseas manager and seizing the amount of $x_{l}$ produced. As in Grossman and Hart (1986), ownership is identified with the residual rights of control over certain assets. In this case, the low-tech input plays the role of this asset. ${ }^{19}$

If there were no costs associated with firing the manufacturing plant manager, there would be no surplus to bargain over after production, and the manufacturing plant manager would $e x$ ante optimally set $x_{l}=0$ (which of course would imply $y=0$ ). In that case, integration would never be chosen. To make things more interesting, I assume that firing the manufacturing plant manager results in a negative productivity shock that leads to a loss of a fraction $1-\delta$ of final-good production. Under this assumption, the surplus of the relationship remains positive even under integration. I take the fact that $\delta$ is strictly less than one as given, but this assumption could be rationalized in a richer framework. ${ }^{20}$

The rest of this section is structured as follows. I will first revisit the static, partial-equilibrium model developed in section I. Next, I will analyze the dynamics of the model and discuss the implications of vertical integration for this new view of the product cycle.

\footnotetext{
${ }^{18}$ To illustrate this point, consider the case in which the Northern productivity advantage in product development is bounded and the production process cannot be fragmented across borders (e.g., because of prohibitive transport costs or communication costs). Under these circumstances, the whole production process would shift from the North to the South at some point along the life-cycle of the good, but the model would deliver no predictions for the dynamic organizational structure of firms.

${ }^{19}$ See Antràs (2003) and Antràs and Helpman (2004) for related set-ups.

${ }^{20}$ The fact that the fraction of final-good production lost is independent of $z$ simplifies the analysis but is not necesary for the qualitative results discussed below.
} 


\section{A. Firm Behavior}

In section I.B, I computed ex-ante profits for the research center under two possible modes of organization: (a) manufacturing by an independent plant in the North; and (b) manufacturing by an independent plant in the South. The possibility of vertical integration introduces two additional options: manufacturing by a vertically integrated plant in the North and manufacturing by a vertically integrated plant in the South. Because contracts are assumed to be perfectly enforceable in transactions involving two firms located in the same country, it is straightforward to show that the first of these new options yields ex-ante profits identical to those in case (a). As is well known from the property-rights literature, in a world of complete contracts, ownership structure is both indeterminate and irrelevant. In contrast, when Southern assembly is chosen, the assignment of residual rights is much more interesting.

\section{(c) Manufacturing by a Vertically-Integrated Plant in the South}

Consider then the problem faced by a research center and its integrated manufacturing plant in the South. If both managers decide to make good-quality intermediate inputs and they agree in the bargaining, the potential revenues from the sale of the final good are again $R=\lambda^{1-\alpha} \zeta_{z}^{\alpha} x_{h}^{\alpha(1-z)} x_{l}^{\alpha z}$. In contrast, if the parties fail to agree in the bargaining, the product-development manager will fire the manufacturing plant manager, who will be left with nothing. The research center will instead be able to sell an amount $\delta y$ of output, which using equation (1) will translate into sale revenues of $\delta^{\alpha} R$. The quasi-rents of the relationship are therefore given by $\left(1-\delta^{\alpha}\right) R$. Symmetric Nash bargaining leaves each party with its default option plus one-half of the quasi-rents. The research center therefore sets $x_{h}$ to maximize $\frac{1}{2}\left(1+\delta^{\alpha}\right) R-w^{N} x_{h}$, while the Southern manufacturing plant simultaneously chooses $x_{l}$ to maximize $\frac{1}{2}\left(1-\delta^{\alpha}\right) R-w^{S} x_{l}$. Relative to case (b) in section I, integration enhances the research center's incentives to invest $\left(\frac{1}{2}\left(1+\delta^{\alpha}\right)>\frac{1}{2}\right)$ but, at the same time, it reduces the manufacturing plant's incentives to invest. Combining the first-order conditions of these two programs yields the following optimal price for the final good:

$$
p_{M}^{S}(z)=\frac{2\left(w^{N}\right)^{1-z}\left(w^{S}\right)^{z}}{\alpha\left(1+\delta^{\alpha}\right)^{1-z}\left(1-\delta^{\alpha}\right)^{z}} .
$$

Incomplete contracting again distorts the optimal price charged for the final good. Notice, however, that in this case the distortions are higher, the higher is $z$. Setting $T$ so as to make the integrated manufacturing plant break even leads to the following expression for the research center's ex-ante 
profits:

$$
\pi_{M}^{S}(z)=\left(1-\frac{1}{2} \alpha\left(1+\delta^{\alpha}(1-2 z)\right)\right) \lambda\left(\frac{2\left(w^{N}\right)^{1-z}\left(w^{S}\right)^{z}}{\alpha\left(1+\delta^{\alpha}\right)^{1-z}\left(1-\delta^{\alpha}\right)^{z}}\right)^{-\alpha /(1-\alpha)}
$$

where the subscript $M$ reflects the fact that the research center becomes a multinational firm under this arrangement.

\section{B. The Equilibrium Choice Revisited}

The product manager will now choose the manufacturing location and ownership structure that maximize profits for a given $z$. Consider first the choice between Northern assembly and Southern assembly by an independent firm. This was analyzed in section I, where I showed that under Assumption 1, there exists a unique $\bar{z}=A^{-1}(\omega)$ such that $\pi^{N}(z)>\pi^{S}(z)$ for $z<\bar{z}$, and $\pi^{N}(z)<\pi^{S}(z)$ for $z>\bar{z}$.

Consider next the choice between Northern assembly and Southern assembly by an integrated firm. Comparing equations (3) and (6), it follows that $\pi_{M}^{S}(z) \geq \pi^{N}(z)$ only if $A_{M}(z) \leq \omega$, where

$$
A_{M}(z)=\left(\frac{1-\alpha}{1-\frac{1}{2} \alpha\left(1+\delta^{\alpha}(1-2 z)\right)}\right)^{(1-\alpha) / \alpha z}\left(\frac{2}{\left(1+\delta^{\alpha}\right)^{1-z}\left(1-\delta^{\alpha}\right)^{z}}\right)^{1 / z}
$$

In the Appendix, I show that $\lim _{z \rightarrow 0} A_{M}(z)=+\infty$ and $A_{M}(z)>1$ for all $z \in[0,1]$. As with the comparison involving arm's length production transfers, when the low-tech input is not very important in production, the cost-saving benefit of producing it in the South is outweighed by the costs of incomplete contracting, which distort the marginal cost of production of both the hi-tech and the low-tech inputs. ${ }^{21}$ It thus follows from this discussion that, as in section I, the low-tech input will again be produced in the North whenever $z$ is sufficiently low, that is, whenever the good is sufficiently unstandardized.

Consider next the choice between Southern assembly by an independent firm (or outsourcing) and Southern assembly by an integrated firm (or insourcing). It is straightforward to check that insourcing will dominate outsourcing whenever $A_{M}(z)<A(z)$, while outsourcing will dominate

\footnotetext{
${ }^{21}$ Crucial for this result is the fact that, following Grossman and Hart (1986), and contrary to the older transactioncost literature, vertical integration does not eliminate the opportunistic behavior at the heart of the hold-up problem. Integration, however, affects the allocation of power in the relationship and this explains why $A_{M}(z)$ is different from $A(z)$ in equation (5).
} 
insourcing whenever $A_{M}(z)>A(z) .{ }^{22}$ Furthermore, the following result - analogous to Proposition 1 in Antràs (2003) - is proved in the Appendix:

Lemma 2 There exists a unique cutoff $\bar{z}_{M S} \in(0,1)$ such that $A_{M}\left(\bar{z}_{M S}\right)=A\left(\bar{z}_{M S}\right)$. Furthermore, $A_{M}(z)<A(z)$ for $0<z<\bar{z}_{M S}$, and $A_{M}(z)>A(z)$ for $\bar{z}_{M S}<z \leq 1$.

Proof. See the Appendix.

This implies that there exists a unique cutoff $\bar{z}_{M S}$ such that insourcing dominates outsourcing for all $z<\bar{z}_{M S}$, with the converse being true for $z>\bar{z}_{M S}$. The logic of this result lies at the heart of Grossman and Hart's (1986) seminal contribution. When contracts governing transactions are incomplete, ex-ante efficiency dictates that residual rights should be controlled by the party undertaking a relatively more important investment in a relationship. If production of the final good requires mostly product development (i.e., $z$ is low), the investment made by the manufacturing plant manager will be relatively small, and thus it will be optimal to assign the residual rights of control to the research center. Conversely, when the low-tech input is important in production, the research center will optimally choose to tilt the bargaining power in favor of the manufacturing plant by giving away these same residual rights.

\section{[FIGURE 3 ABOUT HERE]}

Figure 3 illustrates this point by depicting the amounts of inputs produced under each organizational mode, as well as those prevailing under complete contracting. The curves $M^{*}$ and $R^{*}$ represent the reaction functions $x_{h}^{*}\left(x_{l}\right)$ and $x_{l}^{*}\left(x_{h}\right)$ under complete contracts, with the corresponding equilibrium at point A. Similarly, B and C depict the incomplete-contract equilibria corresponding to arm's length transacting and vertical integration, respectively. It is clear from the graph that incomplete contracting leads to underproduction of both $x_{h}$ and $x_{l}$. The crucial point to notice from Figure 3, however, is that because the manufacturing plant has relatively less bargaining power under integration, the underproduction in $x_{l}$ is relatively higher under integration than under outsourcing. Furthermore, the more important is the low-tech input in production, the more value-reducing will the underinvestment in $x_{l}$ be. It thus follows that profits under integration relative to those under outsourcing will tend to be lower, the more important is the low-tech input in production (i.e., the higher $z$ ).

A corollary of Lemmas 1 and 2 is that, as in section I, when $z$ is sufficiently high (i.e., when $\left.z>\max \left\{\bar{z}, \bar{z}_{M S}\right\}\right)$, the low-tech input will again be produced in the South by a nonintegrated

\footnotetext{
${ }^{22}$ This follows directly from $A(z)=\omega \cdot\left(\pi^{N}(z) / \pi^{S}(z)\right)^{(1-\alpha) / \alpha z}$ and $A_{M}(z)=\omega \cdot\left(\pi^{N}(z) / \pi_{M}^{S}(z)\right)^{(1-\alpha) / \alpha z}$.
} 
manufacturing plant. Remember also that we have established that for sufficiently low $z$, the lowtech input is necessarily produced in the North. It remains to analyze what happens for intermediate values of $z$, where multinational firms may potentially arise.

Notice first that if $A_{M}(z)>\omega$ for all $z \in[0,1]$, Northern assembly strictly dominates Southern insourcing for all $z \in[0,1]$ and multinational firms do not emerge. Furthermore, in such case, the choice between Northern assembly and foreign outsourcing is identical to that in section I. ${ }^{23}$ Let us therefore focus on the case in which $A_{M}(z)<\omega$ for some $z \in[0,1]$. This analysis is simplified by assuming that $\delta$ is not too high, which ensures that the function $A_{M}(z)$ is a decreasing function of $z$ for all $z \in[0,1] .{ }^{24}$ As shown in the Appendix, a sufficient condition for this to be the case is:

Assumption 2: $\delta^{\alpha} \leq 1 / 2$.

Under Assumption 2, there exists a unique cutoff $\bar{z}_{M N}=A_{M}^{-1}(\omega) \in(0,1)$ such that $\pi^{N}(z)>$ $\pi_{M}^{S}(z)$ for $z<\bar{z}_{M N}$, and $\pi^{N}(z)<\pi_{M}^{S}(z)$ for $z>\bar{z}_{M N}$. This in turn implies that the low-tech input will be produced in the North only if $z<\min \left\{\bar{z}, \bar{z}_{M N}\right\}$. Furthermore, it is easily verified that the three thresholds $\bar{z}, \bar{z}_{M N}$, and $\bar{z}_{M S}$ must satisfy one of the following: (i) $\bar{z}_{M S}=\bar{z}=\bar{z}_{M N}$, (ii) $\bar{z}_{M S}<\bar{z}<\bar{z}_{M N}$, or (iii) $\bar{z}_{M N}<\bar{z}<\bar{z}_{M S}{ }^{25}$

\section{[FIGURE 4 ABOUT HERE]}

Figure 4 is instructive in understanding this result. The figure depicts the curves $A(z)$ and $A_{M}(z)$, which under Assumption 2, are both decreasing in $z$. Lemma 2 ensure that these curves intersect just once and that $A(z)>A_{M}(z)$ if and only if $z<\bar{z}_{M S}$. For any relative wage $\omega$, it is clear that either $\bar{z}_{M S}<\bar{z}<\bar{z}_{M N}$ (left panel) or $\bar{z}_{M N}<\bar{z}<\bar{z}_{M S}$ (right panel). The case $\bar{z}_{M S}=\bar{z}=\bar{z}_{M N}$ occurs with probability zero and will be ignored hereafter.

As indicated in both panels in Figure 4, for a low enough value for $z$, the benefits from Southern assembly are too low relative to the distortions from incomplete contracting, and $x_{l}$ is produced in the North. Furthermore, for a sufficiently high value of $z$, a profit-maximizing research center will decide to outsource the manufacturing input to an independent manufacturing plant in the South. Whether for intermediate values of $z$ the research center becomes a multinational firm or

\footnotetext{
${ }^{23}$ In particular, because $A\left(\bar{z}_{M S}\right)=A_{M}\left(\bar{z}_{M S}\right)>\omega$ and given that $A^{\prime}(z)<0$, it must be the case that $\bar{z}>\bar{z}_{M S}$, and thus the equilibrium is as described in Lemma 1.

${ }^{24}$ The $A_{M}(z)$ curve is decreasing in $z$ for low values of $z$ even when $\delta$ approaches one. Assumption 2 rules out cases in which $A_{M}(z)$ might tilt up for high values of $z$. Such cases are discussed in the Appendix. The results are very similar with the exception that under certain parameter values, the model may feature more complex product-cycle dynamics.

${ }^{25}$ To see this, notice for instance that $\bar{z}_{M S}<\bar{z}$ if and only if both $A\left(\bar{z}_{M S}\right)>\omega$ and $A(\bar{z})<A_{M}(\bar{z})$. But the latter can only be true if $A(\bar{z}) / A_{M}(\bar{z})=\omega / A_{M}(\bar{z})<1$, which implies $\bar{z}<\bar{z}_{M N}$.
} 
not depends on parameter values. If $\bar{z}_{M S}<\bar{z}<\bar{z}_{M N}$, then there exists no $z \in[0,1]$ for which $\pi_{M}^{S}(z)>\max \left\{\pi^{N}(z), \pi^{S}(z)\right\}$, and multinational firms do not arise in equilibrium. Conversely, if

$\bar{z}_{M N}<\bar{z}<\bar{z}_{M S}$, multinational firms can arise provided that $z \in\left[\bar{z}_{M N}, \bar{z}_{M S}\right]$. To summarize the results of this section,

Lemma 3 If $\bar{z}_{M S}<\min \left\{\bar{z}, \bar{z}_{M N}\right\}$, the low-tech input in the North for $z<\bar{z}$, and in the South by an unaffiliated party for $z>\bar{z}$. If instead $\bar{z}_{M S}>\min \left\{\bar{z}, \bar{z}_{M N}\right\}$, the low-tech input is produced in the North for $z<\bar{z}_{M N}$, in the South by an affiliated party if $\bar{z}_{M N}<z<\bar{z}_{M S}$, and in the South by an unaffiliated party if $z>\bar{z}_{M S}$.

\section{Dynamics: The Product Cycle}

Consider now the dynamics developed in section I and assume that $\delta$ is also time-invariant, implying that not only $\bar{z}$, but also $\bar{z}_{M N}$ and $\bar{z}_{M S}$ are constant through time. The following is a straightforward corollary of Lemma 3:

Proposition 2 The model displays a product cycle. If $\bar{z}_{M S}<\min \left\{\bar{z}, \bar{z}_{M N}\right\}$, the product cycle is as described in Proposition 1. If instead $\bar{z}_{M S}>\min \left\{\bar{z}, \bar{z}_{M N}\right\}$, the following product cycle emerges. When the good is relatively new, i.e., $t<h^{-1}\left(\bar{z}_{M N}\right)$, the manufacturing stage of production takes place in the North. For an intermediate maturity of the good, $h^{-1}\left(\bar{z}_{M N}\right)<t<h^{-1}\left(\bar{z}_{M S}\right)$, manufacturing is shifted to the South but is undertaken within firm boundaries. When the good is relatively standardized, i.e., $t>h^{-1}\left(\bar{z}_{M S}\right)$, production is shifted to an unaffiliated party in the South.

This is the central result of this paper. It states that if the threshold maturity level $\min \left\{\bar{z}, \bar{z}_{M N}\right\}$ at which manufacturing is shifted to the South is high enough, the transfer of production will occur at arm's length and multinationals will not emerge in equilibrium. Conversely, if this threshold maturity level is low enough, manufacturing will be shifted to the South within the boundaries of the Northern firm by establishing a wholly-owned foreign affiliate. In that case, arm's length assembly in the South will only be observed at a later stage in the life cycle of the good. The model may thus generate both endogenous product cycles as well as endogenous organizational cycles.

\section{Empirical Evidence}

This section reviews some implications of this extended version of the model and contrasts them with the findings of the empirical literature on the product cycle. For simplicity, I will mostly focus 
on the case in which $\bar{z}_{M S}>\min \left\{\bar{z}, \bar{z}_{M N}\right\}$, so that the model features both intrafirm as well as arm's-length production transfers.

Consider first the time-series implications of the model. These are well summarized by Proposition 2. The model predicts that industries will emerge in low-wage countries only with some lag. Furthermore, the model predicts that in the initial phases of the presence of the industry in the South, foreign direct investment from rich countries should constitute an important part of the industry. Eventually, unaffiliated domestic producers should gain the bulk of the Southern market share, but importantly the model predicts that foreign licensing should still play an important role in those later phases.

The model is consistent with the evolution of the Korean electronics industry from the early 1960s to the late 1980s. ${ }^{26}$ In the early 1960s, Korean electronic firms were producing mostly lowquality consumer electronics for their domestic market. The industry took off in the late 1960s with the establishment of a few large U.S. assembly plants, almost all wholly owned, followed in the early 1970 s by substantial Japanese investments. ${ }^{27}$ These foreign subsidiaries tended to assemble components exclusively for export using imported parts. In this initial phase, foreign affiliates were responsible for 71 percent of exports in electronics, with the percentage reaching 97 percent for the case of exports of integrated circuits and transistors, and 100 percent for memory planes and magnetic heads. In the 1970s and 1980s domestic Korean firms progressively gained a much larger market share, but the strengthening of domestic electronic companies was accompanied by a considerable expansion of technology licensing from foreign firms. Indeed, as late as 1988, 60 percent of Korean electronic exports were recorded as part of an Original Equipment Manufacturing (OEM) transaction. ${ }^{28}$ The percentage approached 100 percent in the case of exports of computer terminals and telecommunications equipment. Korean giants such as Samsung or Goldstar were heavily dependent on foreign licenses and OEM agreements even up to the late 1980 s. $^{29}$

At a more micro level, several cross-sectional implications of the model are consistent with the findings of the empirical literature on the product cycle. To see this, imagine attempting to test

\footnotetext{
${ }^{26}$ The following discussion is based on Martin Bloom (1992), UNCTAD (1995, pp. 251-253), and Jin W. Cyhn (2002).

${ }^{27}$ Motorola established a production plant in Korea in 1968. Other U.S. based multinationals establishing subsidiaries in Korea during this period include Signetics, Fairchild and Control Data.

${ }^{28} \mathrm{OEM}$ is a form of subcontracting which as Cyhn's (2002) writes "occurs when a company arranges for an item to be produced with its logo or brand name on it, even though that company is not the producer".

${ }^{29}$ As pointed out by a referee, a caveat in mapping Proposition 2 with the evolution of the Korean electronics industry is that, during this period, Korean wages were growing faster than U.S. wages (i.e., $\omega$ was steadily fall). Notice, however, that because $\bar{z}_{M S}$ is independent of $\omega$, the model would still predict the simple three-stage product cycle provided that $\omega$ does not fall at a rate faster than $A(z)$ and $A_{M}(z)$, as would be the case if the good standardizes at a sufficiently fast rate.
} 
the model with data on a cross-section of production transfers. The model would then predict that the probability of a particular transfer occurring within firm boundaries should be decreasing in the maturity of the product at the time of the transfer. This maturity should in turn be negatively correlated with the age of the product and positively correlated with both its R\&D intensity as well as with its speed of standardization.

Mansfield and Romeo (1980) analyzed 65 technology transfers by 31 U.S.-based firms in a variety of industries. They found that, on average, U.S.-based firms tended to transfer technologies internally to their subsidiaries within 6 years of their introduction in the United States. The average lag for technologies that were transferred through licensing or through a joint venture was instead 13 years. Similarly, after surveying R\&D executives of 30 U.S. based multinational firms, Mansfield, Romeo, and Wagner (1979) concluded that for young technologies (less than 5 years old), internal technology transfer tended to be preferred to licensing, whereas for more mature technologies (between 5 and 10 years), licensing became a much more attractive choice. ${ }^{30}$

In more detailed studies, Davidson and McFetridge $(1984,1985)$ looked at 1,376 internal and arm's-length transactions involving high-technology products carried out by 32 US.-based multinational enterprises between 1945 and 1975. Their logit estimates indicated that the probability of internalization was indeed higher the newer and more radical was a technology and the larger was the fraction of the transferor's resources devoted to scientific R\&D.

There is also some evidence that the probability of internalization might be decreasing in the speed of standardization. Using a sample of 350 US firms, Wilson (1977) indeed concluded that licensing was more attractive the less complex was the good involved, with his measure of complexity being positively correlated with the amount of R\&D undertaken for its production. In their study of the transfer of 35 Swedish innovations, Bruce M. Kogut and Udo B. Zander (1993) similarly found that the probability of internalization was lower the more codifiable and teachable and the less complex was the technology.

The dataset used by Davidson and McFetridge (1985) also includes information on the characteristics of the country receiving the transfer. The model predicts that an equilibrium with multinational firms is more likely the higher is $\bar{z}_{M S}$ relative to the other two thresholds $\bar{z}$ and $\bar{z}_{M N}$. In section I, I showed that $\bar{z}$ is a decreasing function of the relative wage $\omega$. By way of implicit

\footnotetext{
${ }^{30}$ In the previous case of the Korean electronics industry, there is also some evidence that "Northern" firms did not license their leading edge technologies to their Korean licensees. For instance, in 1986, Hitachi licensed to Goldstar the technology to produce the 1-megabyte Dynamic Random Access Memory (DRAM) chip, when at the same time it was shifting to the 4-megabyte DRAM chip. Similarly, Phillips licensed the production of CD players to ten Korean producers, while keeping within firm boundaries the assembly of their deck mechanisms.
} 
differentiation, and making use of Assumption 2, one can show that $\bar{z}_{M N}$ is also decreasing in $\omega$. The choice between an independent and an integrated Southern supplier, as captured by the threshold $\bar{z}_{M S}$ is instead unaffected by the relative wage in the North. ${ }^{31}$ It thus follows that in a cross-section of production transfers, the probability of internalization should be decreasing in the labor costs of the recipient country. This prediction is consistent with the findings of Davidson and McFetridge (1985). In their sample of 1,376 transfers, they found that a higher GNP per capita of the recipient country (arguably, a proxy for $\omega$ in the model) was associated with a lower probability of internalization. Importantly, their results are robust to controlling for several institutional characteristics of the recipient country (remember the discussion in footnote 17). ${ }^{32}$

One further implication of the model is that relative to the case in which only arm's length transactions are permitted, the emergence of intrafirm production transfer by multinational firms accelerates the shift of production towards the South (remember that $\bar{z}_{M N}<\bar{z}$ whenever multinational firms are active in the model). This result fits well Theodore H. Moran's (2001) recent study of the effects of domestic-content, joint-venture, and technology-sharing mandates on production transfer to developing countries. Plants in host countries that impose such restrictions, he writes, "utilize older technology, and suffer lags in the introduction of newer processes and products in comparison to wholly owned subsidiaries without such requirements" (p. 32). He also describes an interesting case study. In 1998, Eastman Kodak agreed to set up joint ventures with three designated Chinese partners. These joint ventures specialized in producing conventional films under the Kodak name. When the Chinese government allowed Kodak to establish a parallel wholly owned plant, Kodak shifted to this affiliate the manufacturing of the latest digitalized film and camera products (p. 36).

\section{Conclusions}

This paper has presented a dynamic model featuring both endogenous product cycles and endogenous organizational cycles. It has been argued that the same forces that make firms choose to manufacture their new goods in high-wage countries can explain why, when they decide to transfer production to low-wage countries, they might choose to do so inside their firm boundaries.

\footnotetext{
${ }^{31}$ This follows directly from the assumption of Cobb-Douglas technology and isolates the partial-equilibrium decision to integrate or outsource from any potential general-equilibrium feedbacks. This implied block-recursiveness is a useful property for solving the general equilibrium version of the model outlined in the Appendix, but the results should be robust to more general specifications of technology.

${ }^{32}$ In parallel work using aggregate industry data from the U.S. Department of Commerce, Farok J. Contractor (1984) found similar results.
} 
In contrast to previous theories of the multinational firm, firm boundaries were not drawn appealing to technological considerations, such as economies of scale or transport costs. ${ }^{33}$ As in Antràs (2003), I instead set forth a purely organizational, property-rights model of the multinational firm. ${ }^{34}$ Multinational firms emerged in equilibrium whenever transaction-cost minimization dictated that certain goods would be transacted more efficiently within firm boundaries than at arm's length. Relative to a world with only arm's length transacting, I showed that foreign direct investment might help alleviate contractual frictions in global production sharing, thereby anticipating the transfer of certain stages of the production to low-wage countries.

The simple model developed here has proven to be a useful lens through which to interpret several findings in the international business literature. Nevertheless, much remains to be done. For instance, the present framework has abstracted from at least one important channel of production transfer, namely, imitation. Future efforts should also be directed at incorporating elements of alternative theories of the firm to the study of international patterns of specialization.

\footnotetext{
${ }^{33}$ This previous literature builds on the seminal work of Helpman (1984) and James R. Markusen (1984), and is extensively reviewed in Richard E. Caves (1996) and Markusen (1995). Wilfred J. Ethier (1986), Ethier and Markusen (1996), and Amy J. Glass and Kamal Saggi (2002) study the choice between foreign direct investment and licensing, but in frameworks in which the internalization decision is unrelated to the allocation of some residual rights of control.

${ }^{34}$ This paper is related to an emerging literature on general-equilibrium models of ownership structure (c.f., John E. McLaren, 2000, Grossman and Helpman, 2002, Antràs, 2003, Antràs and Helpman, 2004). In Antràs (2003), I unveiled two systematic patterns in the volume of intrafirm trade, which I then rationalized in a theoretical framework that combined a Grossman-Hart-Moore view of the firm with a Helpman-Krugman view of international trade. The model was extended in Antràs and Helpman (2004) to account for intraindustry heterogeneity in organizational choices.
} 


\section{Appendix}

\section{A. Some Properties of $A_{M}(z)$}

Here I provide a formal proof that $\lim _{z \rightarrow 0} A_{M}(z)=+\infty$ and that $A_{M}(z)>1$ for all $z \in[0,1]$. It is convenient to start defining $\phi=\frac{1}{2}\left(1+\delta^{\alpha}\right)$ so that

$$
A_{M}(z)=\left(\frac{1-\alpha}{(1-\alpha(\phi(1-z)+(1-\phi) z))}\left(\phi^{1-z}(1-\phi)^{z}\right)^{-\alpha /(1-\alpha)}\right)^{(1-\alpha) / \alpha z}
$$

Now notice that $\lim _{z \rightarrow 0} A_{M}(z)=+\infty$ provided that $\frac{1-\alpha}{(1-\alpha \phi) \phi^{\alpha /(1-\alpha)}}>1$, but this is implied by the fact that $(1-\alpha x) x^{\alpha /(1-\alpha)}$ is increasing in $x$ for $\alpha \in(0,1)$ and $x \in(0,1)$. Next, I show that $\Gamma(\alpha, \phi, z)=$ $\left[A_{M}(z)\right]^{\alpha z /(1-\alpha)}>1$ for all $z \in[0,1]$, which immediately implies $A_{M}(z)>1$ for all $z \in[0,1]$. Since $\Gamma(0, \phi, z)=1$, it is sufficient to show that $\partial \Gamma(\alpha, \phi, z) / \partial \alpha>0$ for all $\alpha \in(0,1), \phi \in(0,1)$, and $z \in[0,1]$. But simple differentiation reveals that $\partial \Gamma(\alpha, \phi, z) / \partial \alpha>0$ if and only if

$$
\ln \left(\frac{1}{\phi^{1-z}(1-\phi)^{z}}\right)>(1-\alpha)\left(\frac{1-\phi(1-z)-(1-\phi) z}{1-\alpha(\phi(1-z)+(1-\phi) z)}\right)
$$

The right-hand side of the inequality is decreasing in $\alpha$, so all we need to show is that

$$
g(z)=\ln \left(\frac{1}{\phi^{1-z}(1-\phi)^{z}}\right)-(1-\phi(1-z)-(1-\phi) z)>0 .
$$

But since $g(z)$ is linear in $z$, it follows that $g(z) \geq \min \{g(0), g(1)\}$. Finally note that for $\phi \in(0,1)$, both $g(0)=\ln \left(\frac{1}{\phi}\right)-1+\phi>0$ and $g(1)=\ln \left(\frac{1}{1-\phi}\right)-\phi>0$. Hence, $g(z)>0$.

\section{B. Proof of Lemma 2}

Let $\Theta(z)=\left(A_{M}(z) / A(z)\right)^{z}$, which using equations (5) and (7) simplifies to

$$
\Theta(z)=\left(\frac{1-\frac{1}{2} \alpha}{1-\frac{1}{2} \alpha(1+\delta(1-2 z))}\right)^{(1-\alpha) / \alpha}\left(\frac{1}{(1+\delta)^{1-z}(1-\delta)^{z}}\right)
$$

Straightforward algebra delivers that $\Theta^{\prime}(z)>0$ if and only if

$$
\ln \left(\frac{1+\delta^{\alpha}}{1-\delta^{\alpha}}\right)>\frac{(1-\alpha) \delta^{\alpha}}{1-\frac{1}{2} \alpha\left(1+\delta^{\alpha}(1-2 z)\right)}
$$

The right hand side is decreasing in $z$ and is therefore no larger than $(1-\alpha) \delta^{\alpha} /\left(1-\frac{1}{2} \alpha\left(1+\delta^{\alpha}\right)\right)$, which in turn can be shown to be smaller than $\ln \left[\left(1+\delta^{\alpha}\right) /\left(1-\delta^{\alpha}\right)\right]$. To see this last statement, simply define the 
function $\vartheta(\delta)=\ln \left[\left(1+\delta^{\alpha}\right) /\left(1-\delta^{\alpha}\right)\right]-(1-\alpha) \delta^{\alpha} /\left(1-\frac{1}{2} \alpha\left(1+\delta^{\alpha}\right)\right)$ and notice it is increasing in $\delta$ and satisfies $\vartheta(0)=0$. We thus conclude that $\Theta^{\prime}(z)>0$ for all $z \in[0,1]$.

Next, the fact that $(1-\alpha x) x^{\alpha /(1-\alpha)}$ is increasing in $x$ for $\alpha \in(0,1)$ and $x \in(0,1)$ implies that $\Theta(0)<1$ and $\Theta(1)>1$. Hence, there exists a unique $\bar{z}_{M S}$ such that $\Theta(z)<1$ for $0<z<\bar{z}_{M S}, \Theta(z)>1$ for $\bar{z}_{M S}<z<1$, and $\Theta(z)=1$ for $z=\bar{z}_{M S}$. Notice that Assumption 2 is not necessary for this result. To complete the proof, note that for $z \in(0,1), A_{M}(z)<A(z)$ if and only if $\Theta(z)<1 ; A_{M}(z)>A(z)$ if and only if $\Theta(z)>1$; and $A_{M}(z)=A(z)$ if and only if $\Theta(z)=1$. Finally, for $z=1$, straightforward manipulation yields $A_{M}(1)>A(1)$.

\section{Discussion of Assumption 2}

As argued in the main text, the proof of Lemma 3 is straightforward when $A_{M}(z)$ is non-increasing in $z$ for all $z \in[0,1]$. Simple differentiation of equation (7) shows that this is the case whenever

$$
r(z, \delta, \alpha)=\ln \left(\frac{1-\frac{1}{2} \alpha\left(1+\delta^{\alpha}(1-2 z)\right)}{1-\alpha}\left(\frac{1}{2}\left(1+\delta^{\alpha}\right)\right)^{\alpha /(1-\alpha)}\right)-\frac{\delta^{\alpha} \alpha z}{1-\frac{1}{2} \alpha\left(1+\delta^{\alpha}(1-2 z)\right)}<0
$$

It is easy to show that $\partial r(\cdot) / \partial z \geq 0$ for all $z \in[0,1]$ (with strict inequality for $z>0$ ), which implies that $A_{M}(z)$ will be decreasing for all $z$ if the slope at $z=1$ is negative. Differentiating $r(1, \delta, \alpha)$ with respect to $\delta$, one can show that the slope at 1 is increasing in $\delta$ and is negative when evaluated at $\delta=(1 / 2)^{1 / \alpha}$. It follows that if $\delta^{\alpha}<1 / 2, A_{M}(z)$ is non-increasing in $z$ for all $z \in[0,1]$.

When $\delta^{\alpha}>1 / 2$, the $A_{M}(z)$ curve will still be decreasing in $z$ for sufficiently low $z$, but it may tilt up when $z$ is sufficiently close to one. In those cases, firm behavior will still be exactly as described in Lemma 3 of section 4 provided that $A_{M}(z)$ equals $\omega$ for only one $z \leq \bar{z} \equiv A^{-1}(\omega)$. In other words, the $A_{M}(z)$ curve may intersect $\omega$ for high values of $z$, but this is immaterial because arm's length transacting dominates insourcing at those values of $z$.

Conversely, when $\delta^{\alpha}>1 / 2$ and $A_{M}(z)$ equals $\omega$ for two values of $z$ less than $\bar{z}$, firm behavior is a bit more complex than as described in Lemma $3 .^{35}$ Denote these two thresholds by $\bar{z}_{M N}$ and $\bar{z}_{M N}^{\prime}$. As in Lemma 3, firms will produce the low-tech input in the North for $z<\bar{z}_{M N}$, and they will contract with an arm's-length Southern producer when $z>\bar{z}_{M S}$. The only difference is that multinational firms will emerge only in the interval $\left(\bar{z}_{M N}, \bar{z}_{M N}^{\prime}\right) \subset\left(\bar{z}_{M N}, \bar{z}_{M S}\right)$, while Northern assembly will be the preferred option not only for $z<\bar{z}_{M N}$ but also for $z \in\left(\bar{z}_{M N}^{\prime}, \bar{z}_{M S}\right)$. In the dynamic extension of the model, this implies that the model may predict that assembly returns to the North for some intermediate levels of standardization.

The economics behind these results are as follows. Incomplete contracting has two effects on profits

\footnotetext{
${ }^{35}$ The convexity of $A_{M}(z)$ in $[0,1]$ ensures that $A_{M}(z)=\omega$ for at most two values of $z$.
} 
- compare equation (3) with equations (4) or (6). On the one hand, contractual frictions lead to underproduction of both $x_{h}$ and $x_{l}$, which translates into lower sale revenues and profits. On the other hand, these frictions create rents, thereby increasing the fraction of revenues that producers are able to capture as operating profits. This second effect is second order in the sense that, holding relative wages constant, operating profits are always higher under complete contracts than under incomplete contracts. This is a desirable property of the model, because the existence of the second effect seems much less robust to alternative modelling strategies. ${ }^{36}$ What matters for Lemma 3, however, is how the overall distortions vary with $z$. This derivative tends to be dominated by the underproduction effect which dictates that $A_{M}(z)$ be a non-increasing function of $z$ for all $z \in[0,1]$. For sufficiently high $\delta$, however, the second effect may actually dominate thus complicating the analysis.

\section{A General Equilibrium Version of the Model}

In this section, I briefly outline how the partial-equilibrium model developed above can be embedded in a general-equilibrium framework with varieties in different sectors featuring different standardization levels. For simplicity, I will only describe the general equilibrium at a particular point in time and will focus on showing that the equilibrium wage in the North is necessarily higher than that in the South. In Antràs (2004), I show that the economy in fact converges to a steady state equilibrium so the analysis below can be interpreted as describing this steady state. I will also restrict the analysis to the case in which intrafirm production transfers are ruled out (as in section I in the main text). In Antràs (2004), I describe the general equilibrium with multinational firms and I also discuss several macroeconomic and welfare implications of the model.

Consider again a world with two countries, the North and the South. The North is endowed with $L^{N}$ units of labor, while the Southern endowment is equal to $L^{S}$. There is a measure $N$ of industries indexed by $j$, each producing an endogenously determined measure $n_{j}$ of differentiated goods. Preferences of the representative consumer in each country are given by:

$$
U=\int_{0}^{N} \log \left(\int_{0}^{n_{j}} y_{j}(i)^{\alpha} d i\right)^{1 / \alpha} d j
$$

Notice that all industries are viewed as symmetric with a unitary elasticity of substitution between them. The varieties of differentiated goods also enter symmetrically into (A1), but with an elasticity of substitution equal to $1 /(1-\alpha)>1$. As is well known, these preferences gives rise to a constant price-elasticity of demand for any variety $i$ in any industry $j, y_{j}(i)=\lambda_{j} p_{j}(i)^{-1 /(1-\alpha)}$, where $\lambda_{j}$ is a function of total world spending

\footnotetext{
${ }^{36}$ In particular, by introducing a rent-absorbing fixed factor in production, this effect would disappear.
} 
$E$ and an industry price index. Because firms take $\lambda_{j}$ as given, each producer of a final-good variety faces a demand function analogous to that in equation (1) in the main text.

Production of each final-good variety is also as described in section I, with the additional assumption that production of each variety also requires a fixed cost of $f$ units of labor in the country where the hitech input is produced (i.e., the North). It is assumed that all producers in a given industry share the same technology as specified in (2), with a common elasticity $z(j)$. To isolate the effect of cross-industry differences in standardization, I assume that the technology for producing intermediate inputs, as well as fixed costs, are identical across industries and varieties. Firm structure is as described above, with the additional assumption that there is free entry, so that the measure $n_{j}$ of varieties in each industry always adjusts so as to make all research centers break even. The contracting environment is also analogous to that of the partial-equilibrium model and, in particular, the parameter $\delta$ is common for all varieties and industries.

Consider then the equilibrium in any industry $j .{ }^{37}$ Facing the same technology and contracting environment, all producers in the same industry will necessarily set the same price and therefore will earn the same profits. It follows that letting again $\bar{z} \equiv A^{-1}(\omega)$, in industry $j$ the low-tech input will be produced in the North if $z(j)<\bar{z}$, and in the South if $z(j)>\bar{z}$, with the choice remaining indeterminate for $z(j)=\bar{z}$. The equilibrium number of varieties produced in industry $j$ can be solved for by using prices to compute $\lambda_{j}$, and then setting operating profits in (3) and (4) equal to fixed costs, as dictated by free entry.

Free entry ensures that profits are zero and thus all income accrues to labor. In the general equilibrium, world income equals world spending on all goods $-w^{N} L^{N}+w^{S} L^{S}=E-$ and the labor market clears in each country. Using these conditions and denoting by $F(z)$ the fraction of industries with $z(j)<\bar{z}$, one can derive the following equation linking the threshold $\bar{z}$ and the relative wage $\omega$ (see Antràs, 2004, for details):

$$
\omega=B(\bar{z}) \equiv \frac{2-\alpha \int_{\bar{z}}^{1} z f(z) d z}{\alpha \int_{\bar{z}}^{1} z f(z) d z} \frac{L^{S}}{L^{N}},
$$

where $f(z)$ is the probability density function associated with $F(z) . B(\bar{z})$ is an increasing function of $\bar{z}$ satisfying $B(0)>0$ and $\lim _{\bar{z} \rightarrow 1} B(\bar{z})=+\infty$. Intuitively, the higher is $\bar{z}$, the lower is labor demand in the South for a given $\omega$, so an increase in $\omega$ is necessary to bring the Southern labor market back to equilibrium. When $\bar{z}$ goes to 1 , labor demand in the South goes to 0 , and the required relative wage goes to $+\infty$. Figure 5 depicts the curve $B(\cdot)$ in the $(z, \omega)$ space.

\section{[FIGURE 5 ABOUT HERE]}

\footnotetext{
${ }^{37}$ The unit elasticity of substitution between varieties in different industries implies that we can analyze firm behavior in each industry independently. This assumption, which is made for tractability, comes at the cost of obscuring potentially interesting cross-industry interactions in the production transfer decision.
} 
The other equilibrium condition that pins down $\bar{z}$ and $\omega$ comes from the partial equilibrium in section I. In particular, since $\alpha$ is common across industries, $\bar{z}$ is also common across industries and is implicitly defined by the equal profitability condition $\omega=A(\bar{z})$, where $A(\cdot)$ is defined in equation (5). The function $A(\cdot)$ is depicted in Figure 5 together with the function $B(\cdot)$. It is apparent from Figure 5 that there exists a unique equilibrium pair $(\bar{z}, \omega)$. Furthermore, the fact that $A(1)$ is greater than 1 ensures that the equilibrium wage in the North is higher than that in the South, i.e., $\omega>A(1)>1$. This implies that Assumption 1 in section I necessarily holds in the general equilibrium, thus granting validity to the analysis in sections I and II. $^{38}$

It is interesting to notice that in spite of the heterogeneity in industry product-cycle dynamics, the crosssectional picture that emerges from the model is very similar to that in the classical Ricardian model with a continuum of goods of Dornbusch et al. (1977). Notice, however, that comparative advantage as represented by the curve $A(\cdot)$ is here endogenous and arises from a combination of the Northern productivity advantage in product development, the continuous standardization of goods, and the fact that contracts are incomplete. Several implications of this general equilibrium version of the model are studied in Antràs (2004).

\footnotetext{
${ }^{38}$ The general equilibrium corresponding to the partial equilibrium model in section II is discussed in Antràs (2004).
} 


\section{References}

Acemoglu, Daron; Johnson, Simon and Robinson, James A. "The Colonial Origins of Comparative Development: An Empirical Investigation." American Economic Review, December 2001, 91 (5), pp. 1369-1401.

Aghion, Philippe; Dewatripont, Mathias and Rey, Patrick. "Renegotiation Design with Unverifiable Information." Econometrica, March 1994, 62(2), pp. 257-282.

Antràs, Pol. "Firms, Contracts, and Trade Structure." Quarterly Journal of Economics, November 2003, 118(4), pp. 1375-1418.

• "Incomplete Contracts and the Product Cycle." Harvard Institute of Economic Research Working Paper, 2004.

Antràs, Pol and Helpman, Elhanan. "Global Sourcing." Journal of Political Economy, June 2004, 112(3), pp. 552-580.

Bloom, Martin. Technological Change in the Korean Electronics Industry. Paris: OECD, 1992.

Caves, Richard E. (1996), Multinational Enterprise and Economic Analysis. Cambridge, UK: Cambridge University Press, 1996.

Che, Yeon-Koo and Hausch, Donald B. "Cooperative Investments and the Value of Contracting." American Economic Review, March 1999, 89(1), pp. 125-147.

Contractor, Farok J. "Choosing between Direct Investment and Licensing: Theoretical Considerations and Empirical Tests." Journal of International Business Studies, Winter 1984, 15(3), pp. 167-188.

Cyhn, Jin W. Technology Transfer and International Production: The Development of the Electronics Industry in Korea. Cheltenham: Edward Elgar, 2002.

Davidson, William H. and McFetridge, Donald G. "International Technology Transactions and the Theory of the Firm." Journal of Industrial Economics, March 1984, 32(3), pp. 253-264.

. "Key Characteristics in the Choice of International Technology Transfer Mode." Journal of International Business Studies, Summer 1985, 16(2), pp. 5-21.

Dornbusch, Rudiger; Fischer, Stanley and Samuelson, Paul A. "Comparative Advantage, Trade and Payments in a Ricardian Model with a Continuum of Goods." American Economic Review, December 1977, 67(5), pp. 823-839. 
Ethier, Wilfred J. "The Multinational Firm." Quarterly Journal of Economics, March 1986, 101(4), pp. 805-833.

Ethier, Wilfred J. and Markusen, James R. "Multinational Firms, Technology Diffusion and Trade." Journal of International Economics, August 1996, 41(1-2), pp. 1-28.

Feenstra, Robert C. "Integration of Trade and Disintegration of Production in the Global Economy." Journal of Economic Perspectives, Autumn 1998, 12(4), pp. 31-50.

Glass, Amy J. and Saggi, Kamal. "Licensing versus Direct Investment: Implications for Economic Growth." Journal of International Economics, January 2002, 56(1), pp. 131-153.

Grossman, Sanford J. and Hart, Oliver D. "The Costs and Benefits of Ownership: A Theory of Vertical and Lateral Integration." Journal of Political Economy, August 1986, 94(4), pp. 691-719.

Grossman, Gene M. and Helpman, Elhanan. "Endogenous Product Cycles." Economic Journal, September 1991a, 101(408), pp. 1214-1229.

• "Quality Ladders and Product Cycles." Quarterly Journal of Economics, May 1991b, 106:2, pp. $557-586$.

. "Integration vs. Outsourcing in Industry Equilibrium." Quarterly Journal of Economics, February 2002, 117(1), pp. 85-120.

Gruber, William; Mehta, Dileep and Vernon, Raymond. "The R \& D Factor in International Trade and International Investment of United States Industries." Journal of Political Economy, February 1967, 75(1), pp. 20-37.

Hall, Robert E. and Jones, Charles I. "Why Do Some Countries Produce So Much More Output per Worker than Others?" Quarterly Journal of Economics, February 1999, 114(1), pp. 83-116.

Hart, Oliver D. and Moore, John H. "Property Rights and the Nature of the Firm." Journal of Political Economy, December 1990, 98(6), pp. 1119-1158.

Helpman, Elhanan. "A Simple Theory of International Trade with Multinational Corporations." Journal of Political Economy, June 1984, 92(3), pp. 451-471.

Hirsch, Seev. Location of Industry and International Competitiveness. Oxford: Clarendon Press, 1967.

Jensen, Richard A. and Thursby, Marie C. "A Decision Theoretic Model of Innovation, Technology Transfer, and Trade." Review of Economic Studies, October 1987, 54(4), pp. 631-647. 
Kogut, Bruce M. and Zander, Udo B. "Knowledge of the Firm and the Evolutionary Theory of the Multinational Corporation." Journal of International Business Studies, December 1993, 24(4), pp. 625-645.

Krugman, Paul. "A Model of Innovation, Technology Transfer, and the World Distribution of Income." Journal of Political Economy, April 1979, 87(2), pp. 253-266.

McLaren, John E. "Globalization and Vertical Structure." American Economic Review, December 2000, 90(5), pp. 1239-1254.

Mansfield, Edwin and Romeo, Anthony A. "Technology Transfer to Overseas Subsidiaries by U.S.Based Firms." Quarterly Journal of Economics, December 1980, 95(4), pp. 737-750.

Mansfield, Edwin; Romeo, Anthony A. and Wagner, Samuel. "Foreign Trade and U. S. Research and Development." Review of Economics and Statistics, February 1979, 61(1), pp. 49-57.

Markusen, James R. "Multinationals, Multi-Plant Economies, and the Gains from Trade." Journal of International Economics, May 1984, 16(3-4), pp. 205-226.

• "The Boundaries of Multinational Enterprises and the Theory of International Trade." Journal of Economic Perspectives, Spring 1995, 9(2), pp. 169-189.

Moran, Theodore H. Parental Supervision: The New Paradigm for Foreign Direct Investment and Development, Washington, DC: Institute for International Economics, 2001.

Nöldeke, Georg and Schmidt, Klaus M. "Option Contracts and Renegotiation: A Solution to the Hold-up Problem." RAND Journal of Economics, Summer 1995, 26(2), pp. 163-179.

Parry, Thomas G. "The Product Cycle and International Production: U.K. Pharmaceuticals." Journal of Industrial Economics, September 1975, 24(1), pp. 21-28.

Segerstrom, Paul S.; Anant, T. C. A. and Elias Dinopoulos. "A Schumpeterian Model of the Product Life Cycle." American Economic Review, December 1990, 80(5), pp. 1077-1091.

UNCTAD. World Investment Report: Transnational Corporations and Competitiveness. New York: United Nations, 1995.

Vernon, Raymond. "International Investment and International Trade in the Product Cycle." Quarterly Journal of Economics, May 1966, 80(2), pp. 190-207.

Wells, Louis T. Jr. "Test of a Product Cycle Model of International Trade: U.S. Exports of Consumer Durables." Quarterly Journal of Economics, February 1969, 83(1), pp. 152-162. 
Williamson, Oliver E. The Economic Institutions of Capitalism. New York: Free Press, 1985.

Wilson, Robert W. "The Effect of Technological Environment and Product Rivalry on R\&D Effort and Licensing of Inventions." Review of Economics and Statistics, May 1977, 59(2), pp. 171-178.

Yi, Kei-Mu, "Can Vertical Specialization Explain the Growth of World Trade?" Journal of Political Economy, February 2003, 111(1), pp. 52-102. 


\section{Aknowledgements}

*Department of Economics, Harvard University, Littauer 230, Cambridge, MA 02138, National Bureau of Economic Research, and Centre for Economic Policy Research (email: pantras@fas.harvard.edu). I am grateful to Daron Acemoglu, Marios Angeletos, Gene Grossman, and Jaume Ventura for invaluable guidance, and to Richard Baldwin, Lucia Breierova, Francesco Franco, Gordon Hanson, Elhanan Helpman, Simon Johnson, Giovanni Maggi, Marc Melitz, and Roberto Rigobon for their helpful comments and suggestions. The paper was substantially improved by the thoughful comments of the Editor and two anonymous referees. I have also benefited from suggestions by seminar participants at various institutions. The first draft of this paper was written while visiting the International Economics Section at Princeton University, whose hospitality is gratefully aknowledged. I have also benefited from financial support from the Bank of Spain. All remaining errors are my own. 
Figure 1: Timing of Events

\begin{tabular}{|cccc|}
\hline & & & \\
\hline $\mathrm{t}_{0}$ & $\mathrm{t}_{1}$ & $\mathrm{t}_{2}$ & $\mathrm{t}_{3}$ \\
$\begin{array}{l}\text { Choice of where } x_{h} \\
\text { and } x_{l} \text { are produced } \\
\text { Ex-ante transfer } T\end{array}$ & $x_{h}$ and $x_{l}$ produced & $\begin{array}{l}\text { Symmetric Nash } \\
\text { bargaining }\end{array}$ & $\begin{array}{l}\text { Final good pro- } \\
\text { duced and sold }\end{array}$ \\
\hline
\end{tabular}

Figure 2: The Choice of Location

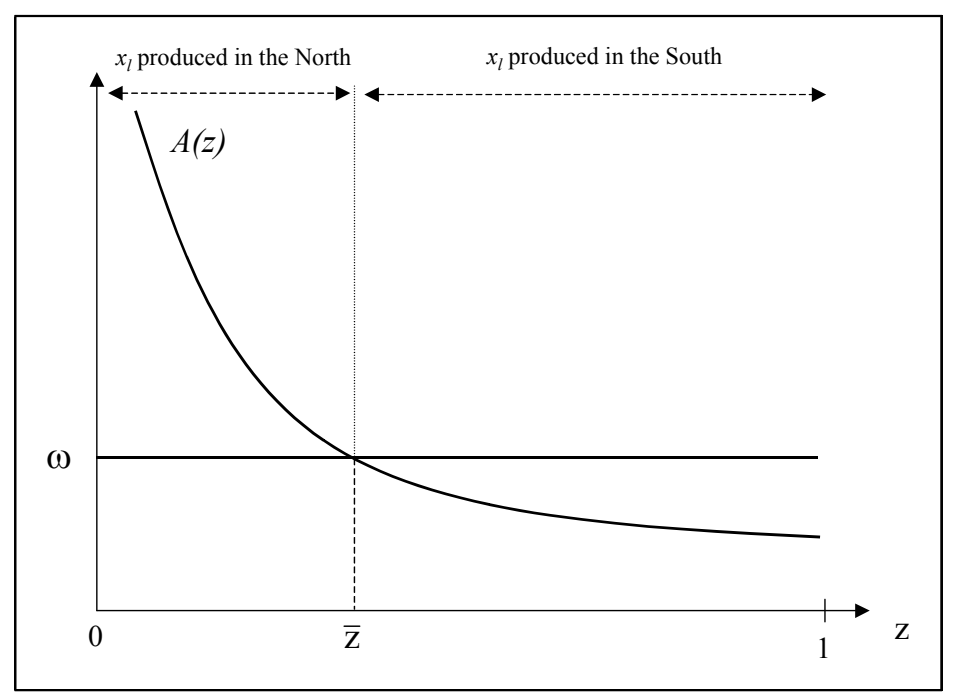

Figure 3: Underproduction and Ownership Structure

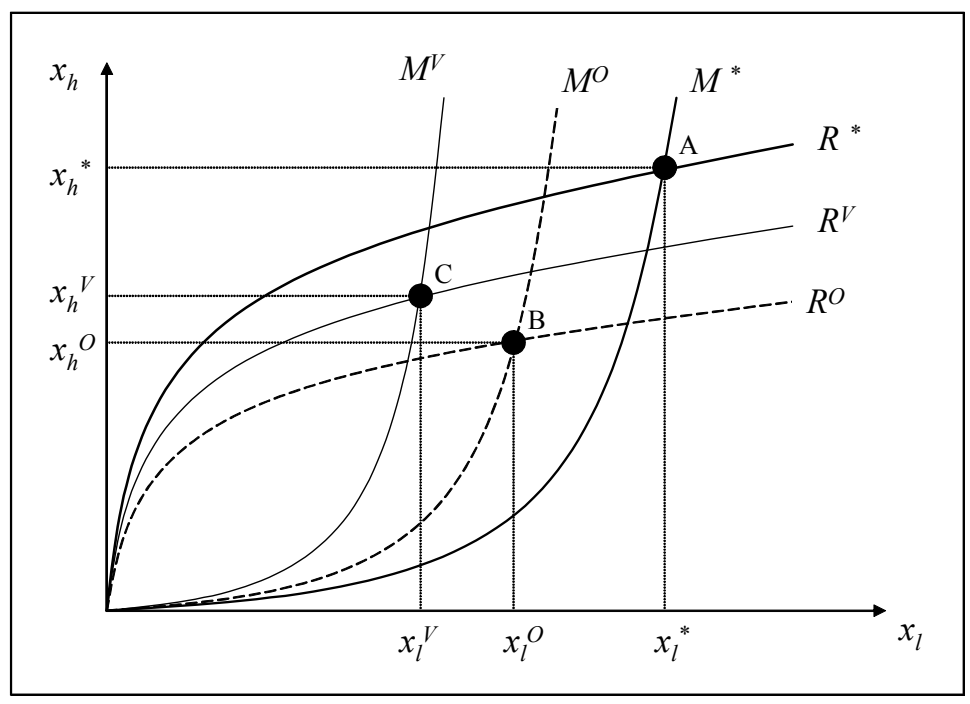


Figure 4: Firm Boundaries and the Product Cycle

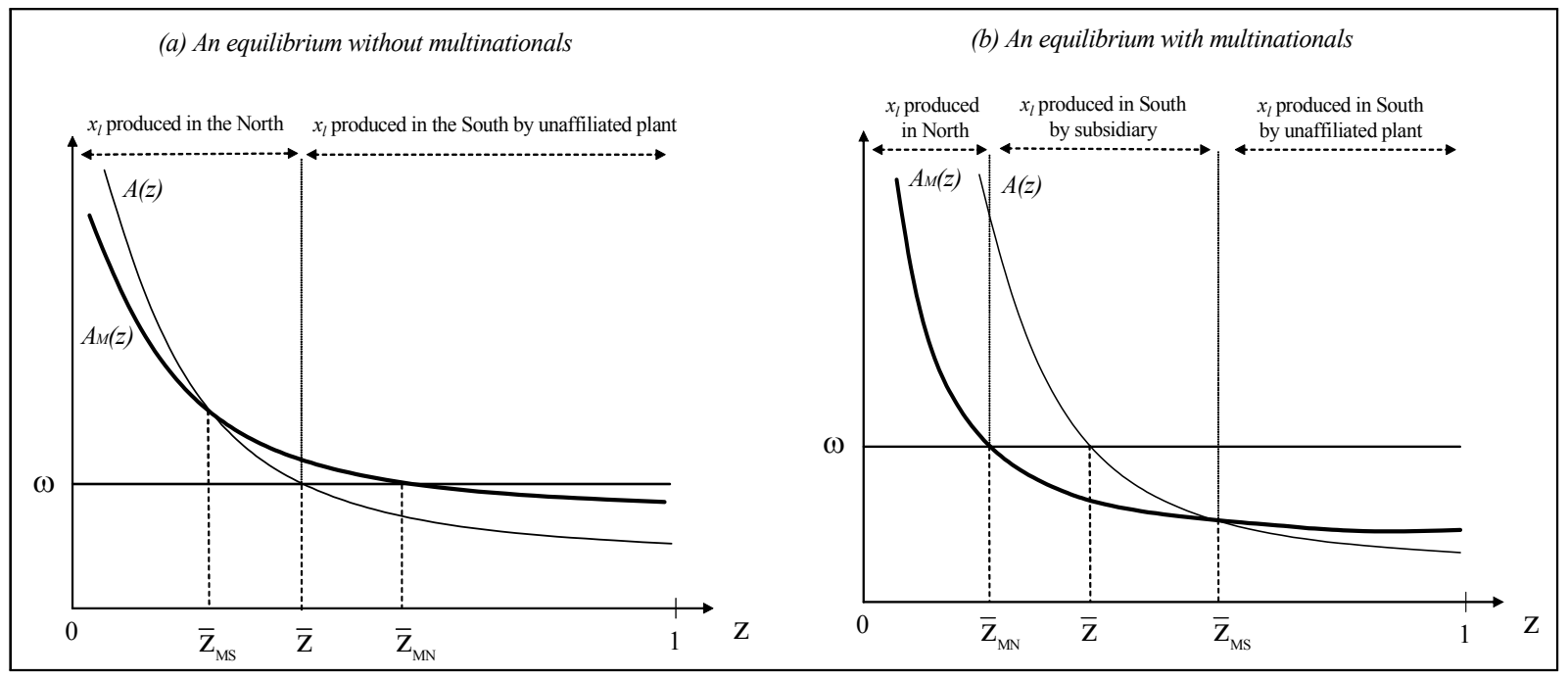

Figure 5: General Equilibrium

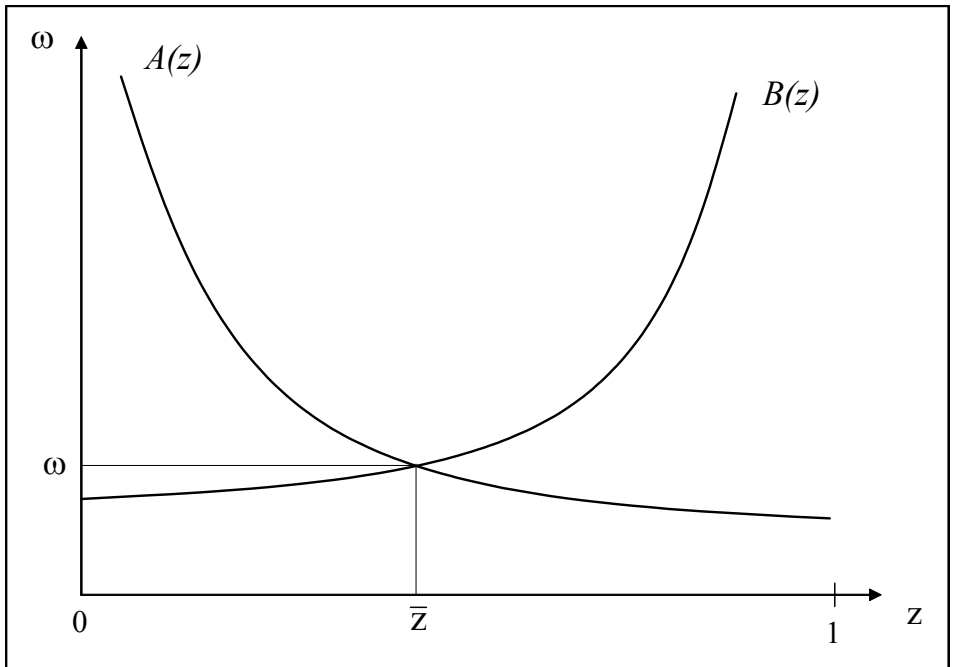

